Algebra Univers. 62 (2009) 151

DOI 10.1007/s00012-010-0067-2

Published online June 10, 2010

Algebra Universalis

(C) Springer Basel AG 2010

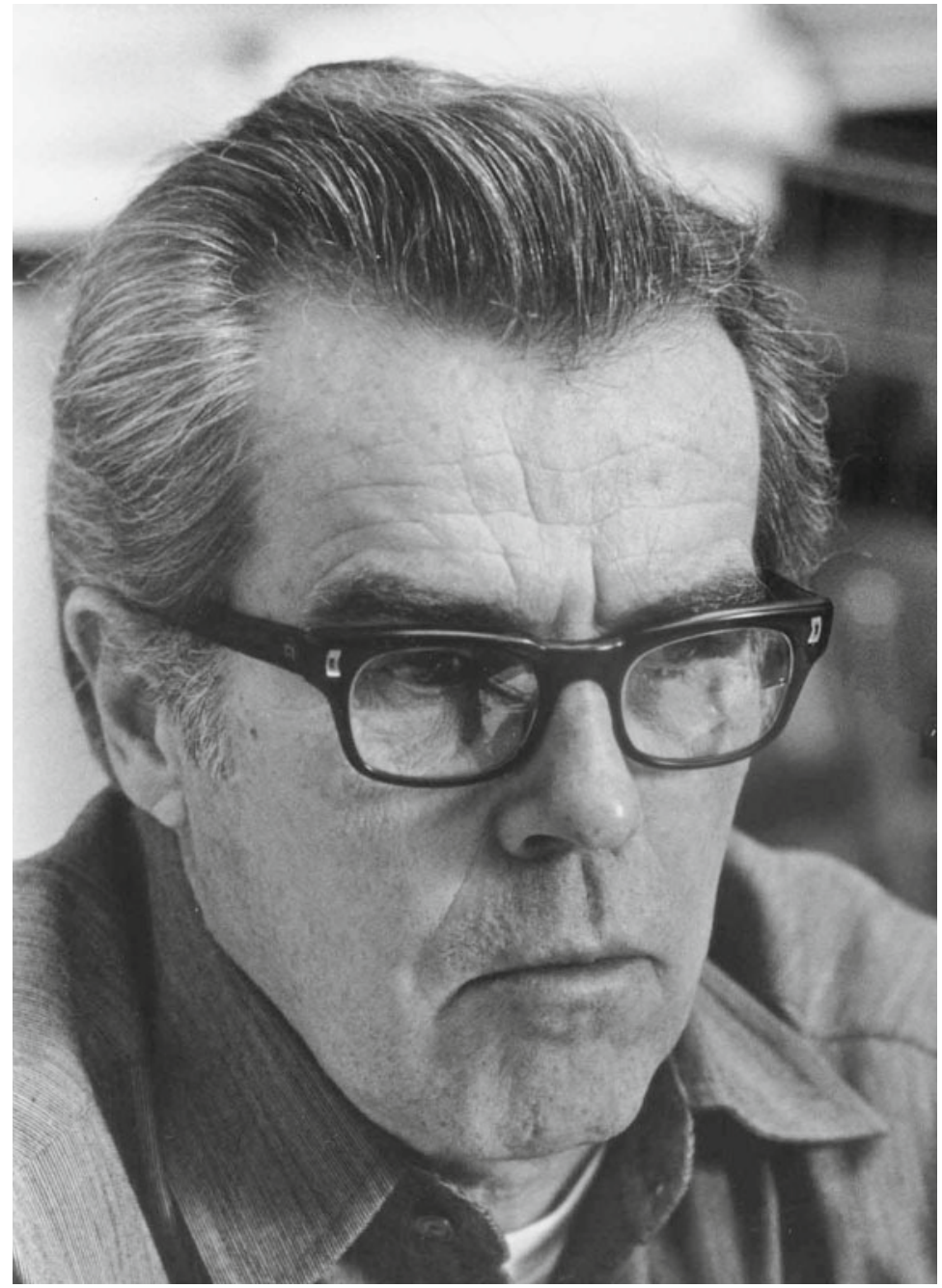

\title{
Paul F. Conrad 1921-2006
}

This issue of Algebra Universalis is dedicated to the memory of Paul F. Conrad. 